\title{
Combined expression of p53, cyclin D1 and epidermal growth factor receptor improves estimation of prognosis in curatively resected oral cancer
}

\author{
Masayuki Shiraki ${ }^{1}$, Tetsuyo Odajima ${ }^{2}$, Tatsuru Ikeda ${ }^{2}$, Aya Sasaki ${ }^{2}$, Masaaki Satoh ${ }^{2}$, \\ Akira Yamaguchi ${ }^{1}$, Makoto Noguchi ${ }^{1}$, Itaru Nagai ${ }^{1}$ and Hiroyoshi Hiratsuka ${ }^{1}$ \\ ${ }^{1}$ Department of Oral Surgery, Sapporo Medical University School of Medicine, Sapporo, Japan and \\ ${ }^{2}$ Department of Pathology, Sapporo Medical University Hospital, Sapporo, Japan
}

\begin{abstract}
p53, cyclin D1 and epidermal growth factor receptor (EGFR) are molecular markers that regulate the cell cycle or cell growth and play important roles in tumor development and progression. In this study, we examined the impact of immunohistochemical expression of these markers on tumor progression in 140 oral cancers. p53, cyclin D1 and EGFR were expressed in 64 cases (46\%), 54 cases (39\%) and 54 cases (39\%), respectively, but there was no inter-relationship between any two of these markers. In the association of these markers with clinicopathological features, EGFR expression alone was significantly associated with poor differentiation $(P=0.0008)$ and invasive growth pattern $(P=0.0003)$. Any of these markers, including EGFR, had no significant impact on survival. Coexpression of all these markers, however, was significantly associated with invasive growth pattern $(P=0.0149)$ and shortened survival $(P=0.0181)$, and was a significant and independent unfavorable prognostic factor $(P=0.0002)$, along with tumor size $(P=0.0040)$, nodal metastasis $(P=0.0137)$ and growth pattern $(P=0.0017)$ in a multivariate analysis. Simultaneous coexpression of these markers in oral cancers might prove to be a useful indicator for identification of low- or high-risk patients.

Modern Pathology (2005) 18, 1482-1489. doi:10.1038/modpathol.3800455; published online 8 July 2005
\end{abstract}

Keywords: oral cancer; p53; cyclin D1; EGFR; coexpression; prognosis

Biological phenotypes of cancer greatly affect the clinical outcomes of patients with the disease. If such biological characteristics of cancer could be predicted before treatment, it would be possible to select more effective and suitable treatment for each cancer. Recent studies have clarified that a variety of molecular events play extremely important roles in not only tumor development but also tumor progression. Consequently, special attention has turned to molecular markers as a possible means for obtaining useful information to predict aggressive phenotypes of tumors. ${ }^{1}$

The molecular markers of interest are those involved in cell cycle regulation of tumor cells and a group of growth factors, since cancer is caused by uncontrolled proliferation of cells, which is itself

Correspondence: Associate Professor T Odajima, DDS, PhD, Department of Pathology, Sapporo Medical University Hospital, South 1, West 16, Chuo-ku, Sapporo 060-0061, Japan.

E-mail: odajima@sapmed.ac.jp

Received 11 March 2005; revised 19 May 2005; accepted 20 May 2005; published online 8 July 2005 induced by abnormalities of cell cycle regulatory mechanisms or activation of growth factors. The p53 tumor-suppressor gene regulates cell cycle progression through induction of apoptosis at the G1/S checkpoint. $^{2,3}$ Immunohistochemical p53 protein expression is based on the prolonged half-life of the mutant protein compared to the wild-type. ${ }^{4}$ Cyclin D1 plays a central role in the G1/S cell cycle transition and responses to cytotoxic stimuli. ${ }^{5,6}$ Epidermal growth factor receptor (EGFR), a transmembranous protein that binds to ligands such as EGF and transforming growth factor- $\alpha$, activates protein-tyrosine kinase, which mediates the signaling involved in cell proliferation and differentiation. ${ }^{7}$ Apart from the well-established prognostic indicators of TNM staging and mode of invasion, these markers have high prognostic values in human cancer, ${ }^{8-21}$ although there are some discrepancies. ${ }^{22-24}$

In view of the prospective impact of multiple molecular marker accumulation on tumor progression, multiple-marker testing could provide us with more useful information for our definition of the biological behavior of oral cancer than single marker 
expression. However, p53, cyclin D1 and EGFR have never been analyzed together in a multiparametric approach for predicting outcome in head and neck cancers. In this study, we examined the prognostic significance of the combined expression of these markers in a large series of 140 curatively resected oral cancers. This prospective study is, to our knowledge, the first report that has examined the impact of combined expression of these markers, using immunohistochemistry, on clinicopathological features and clinical outcomes in oral cancer.

\section{Materials and methods}

\section{Samples}

The study group comprised 140 patients with oral cancer (squamous cell carcinoma) who had undergone curative surgery at the Department of Oral Surgery, Sapporo Medical University School of Medicine, between 1986 and 1998. Patients who died of another cancer or other disease, and those who died within 1 month after curative surgery, were excluded from the current study. The median follow-up for all patients was 66 (range: 5-134) months. Of the140 patients, 98 (70\%) were male and $42(30 \%)$ female, and the mean age was 59 (range: 26-85) years. Tumors occurred in the tongue in 71 patients, gingiva in 28 patients, floor of the mouth in 28 patients, buccal mucosa in 12 patients and lip in only one patient. Tumor size, nodal status, clinical stage, histological grade (grade of tumor differentiation) and tumor growth pattern (mode of invasion) were available for all patients. The clinical stage was defined according to the UICC criteria (1997) and the histological grade according to the WHO tumor classification (2000). The tumor growth pattern was subgrouped according to our previous study. ${ }^{25}$

Tumor samples were obtained at the time of either incisional biopsy for initial diagnosis or excisional biopsy under snap-frozen section control. For histopathological and immunohistochemical studies, tumor samples and nontumorous oral mucosal specimens were fixed in $10 \%$ buffered formalin, and then embedded in paraffin.

\section{Immunohistochemistry}

Sections ( $4 \mu \mathrm{m}$ thick) cut from paraffinized blocks served for histological and immunohistochemical analyses. These tissue sections included not only tumor lesions but also adjacent nontumorous oral epithelia that served as internal controls for immunohistochemistry. The method employing the streptavidin-biotin-peroxidase complex was performed using a SAB-PO kit (Nichirei, Tokyo, Japan) according to the manufacturer's manual. Briefly, dewaxed sections were autoclaved in $10 \mathrm{mM}$ citrate buffer ( $\mathrm{pH}$ 6.0) at $121^{\circ} \mathrm{C}$ for $10 \mathrm{~min}$ for antigen retrieval and then preincubated with $3 \% \mathrm{H}_{2} \mathrm{O}_{2}$ in methanol for $10 \mathrm{~min}$ to block endogenous peroxidase activity. Sections were then blocked with $10 \%$ normal rabbit serum for $10 \mathrm{~min}$ to reduce nonspecific antibody binding and thereafter incubated overnight at $4{ }^{\circ} \mathrm{C}$ with monoclonal antibodies to p53 (1:100; clone DO-7; DAKO, Carpinteria, CA, USA), cyclin D1 (1:50; clone 5D4; Medical Biology Laboratories, Nagoya, Japan) and EGFR (1:40; sc-03; Santa Cruz Biotechnology, Santa Cruz, CA, USA). After washing with phosphate-buffered saline (PBS), the sections were incubated for $15 \mathrm{~min}$ with a biotinylated secondary antibody, followed by the incubation with peroxidase-labeled streptavidin for $15 \mathrm{~min}$. Color visualization was obtained using a DAKO Liquid DAB + Substrate-Chromogen System (DAKO, Carpinteria, CA, USA) according to the manufacturer's manual. Hematoxylin was used as a counterstain. Each experiment included a negative control in which the primary antibodies were replaced by PBS. As positive controls, sections of esophagus, colon or breast cancer known to be positive for each molecular marker were used for each staining.

\section{Evaluation for Expression of Molecular Markers}

The results of the immunohistochemical staining were evaluated independently by three of the authors (pathologists TO, TI, MS) who were unaware of clinical data at the time of reading. Disagreements in evaluation were resolved by review and discussion at a multiheaded microscope. The immunohistochemical evaluation was carried out for tumor areas including the invasion front, which was regarded as most indicative of the biological activity of a tumor, in 10 random highpower fields $(\times 400)$. In all the tumors, about 15002000 tumor cells were observed at a magnification of $\times 400$ on 10 randomly selected fields of the tumor tissues. In the immunohistochemical assessment for molecular markers, tumors were classified as positive or negative for statistical analysis. For p53 and cyclin D1 tumors were evaluated as positive if over $10 \%$ of tumor cells displayed moderate to strong nuclear staining and as negative if otherwise, as reported previously. ${ }^{9,20}$ EGFR expression was evaluated semiquantitatively by slight modifications of the scoring systems proposed previously ${ }^{21,26}$ for distribution (\%) and intensity of membranous and/ or cytoplasmic staining. Scores representing the percentage of stained tumor cells were as follows: 0 , no stained cells; $1,1-30 \% ; 2,31-50 \%$; and 3 , $>50 \% .^{21}$ Intensity was graded from 0 (no staining) to 3 (strong) in comparison with the normal oral epithelium as for membranous expression of EGFR. ${ }^{21,26}$ The final score was calculated by adding the scores for percentage and intensity. Tumors were evaluated as EGFR positive if the final score was 5 or 6 and as negative if otherwise. 


\section{Statistical Analysis}

The association between expression of a marker and clinicopathological features was examined using the $\chi^{2}$ test. Survival analyses were performed by the Kaplan-Meier method, and the statistical difference was analyzed by the log-rank test. To evaluate the effects of molecular markers on the clinicopathological features and the patients' prognoses, multivariate analysis using the Cox stepwise proportional-hazards model was performed on these tumors. A hazard ratio of 1 indicates equivalence for the different levels of a factor. For all statistical analyses, $P<0.05$ was considered to be significant.

\section{Results}

\section{Expression of Molecular Markers in Normal Oral} Epithelia and Oral Cancers

In general, p53 and cyclin D1 immunoreactivities were not found in normal oral epithelia that served as controls, but occasionally, in some cases, very slight nuclear p53 reactivities were expressed in nontumorous oral epithelia adjacent to tumors. In contrast, membranous EGFR immunoreactivities could be regularly demonstrated in the basal and suprabasal layers of normal oral epithelia (Figure 1).

In oral cancers, immunoreactivities for the molecular markers were detected in a subset of tumors. Figure 2 is a case of simultaneous coexpression of all three markers in tumor. Nuclear p53 (Figure 2a) and cyclin D1 (Figure 2b) immunoreactivities were frequently found in tumor cells, but not in stromal cells. In addition to the usual membranous staining, abnormal cytoplasmic expression of EGFR was frequently observed in tumor cells (Figure 2c). The positive rates for the molecular markers were $46 \%$ (64/140) for p53 and 39\% (54/140) for both cyclin D1 and EGFR. There was no statistically significant association between any two of these markers,

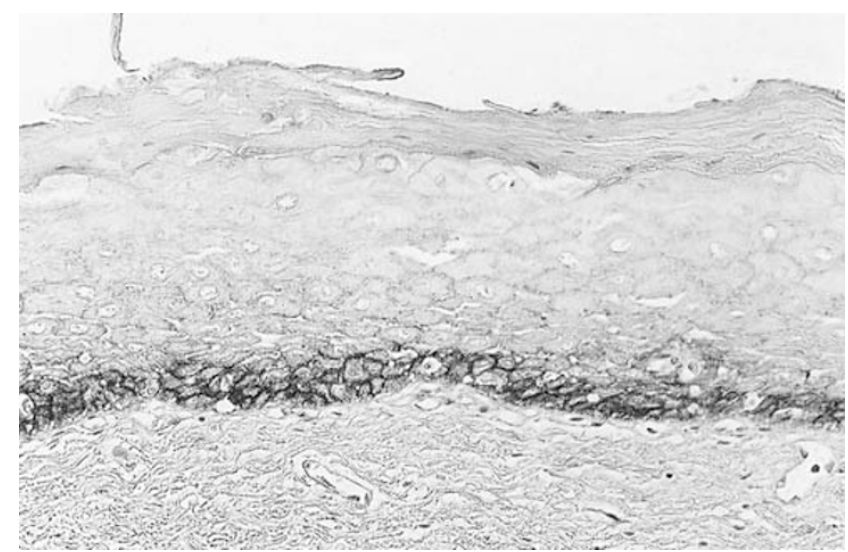

Figure 1 Membranous EGFR expression in oral mucosa. Nuclear counterstaining with hematoxylin. Original magnification $\times 170$. although cyclin D1 and EGFR tended to be correlated $(P=0.0651)$ (Table 1$)$.

\section{Association between Expression of Molecular Marker and Clinicopathological Features in Oral Cancers}

There was no statistically significant association between p53 or cyclin D1 expression and any clinicopathological feature, whereas EGFR expression was significantly associated with poor tumor differentiation $(P=0.0008)$ and invasive growth
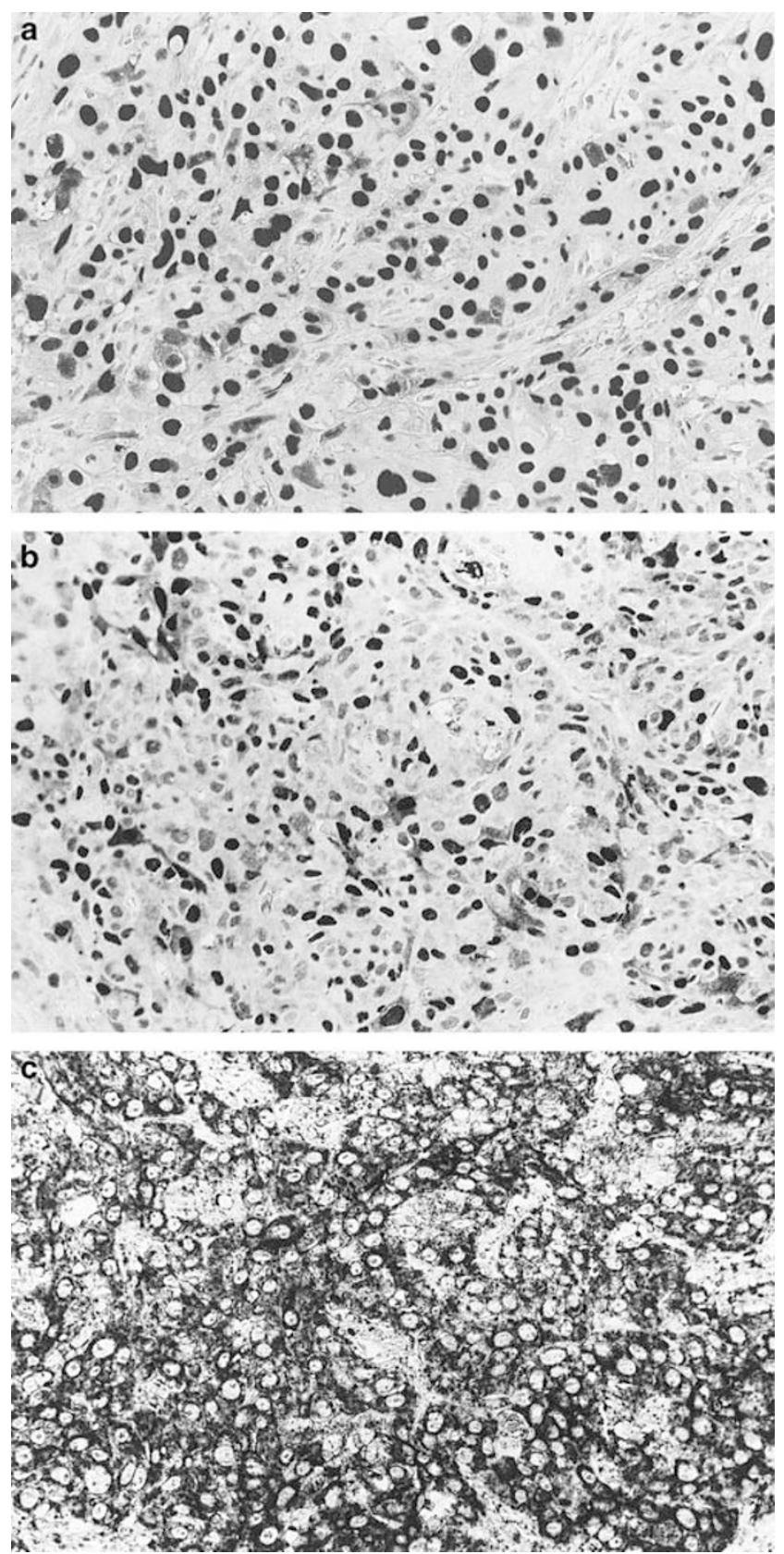

Figure 2 Simultaneous coexpression of nuclear p53 (a), nuclear cyclin D1 (b) and membranous and cytoplasmic EGFR (c) in an oral SCC. Nuclear counterstaining with hematoxylin. Original magnification $\times 170$. 
Table 1 Relationships between p53, cyclin D1 and EGFR expression in oral cancers

\begin{tabular}{|c|c|c|c|c|c|c|c|}
\hline \multirow[t]{2}{*}{ Molecular marker } & \multirow[t]{2}{*}{$\mathrm{n}$} & \multicolumn{3}{|c|}{ p53 } & \multicolumn{3}{|c|}{ Cyclin D1 } \\
\hline & & Negative & Positive & $\mathrm{P}$-value & Negative & Positive & $\mathrm{P}$-value \\
\hline \multicolumn{8}{|l|}{ Cyclin D1 } \\
\hline Negative & 86 & 49 & 37 & 0.4199 & & & \\
\hline Positive & 54 & 27 & 27 & & & & \\
\hline \multicolumn{8}{|l|}{ EGFR } \\
\hline Negative & 86 & 51 & 35 & 0.1327 & 58 & 28 & 0.0651 \\
\hline Positive & 54 & 25 & 29 & & 28 & 26 & \\
\hline
\end{tabular}

Table 2 Relationships between expression of molecular markers and clinicopathological features in oral cancers

\begin{tabular}{|c|c|c|c|c|c|c|c|}
\hline \multirow[t]{3}{*}{ Variable } & \multirow[t]{3}{*}{$\mathrm{n}$} & \multicolumn{6}{|c|}{ Expression of molecular markers } \\
\hline & & \multicolumn{2}{|c|}{$p 53$} & \multicolumn{2}{|c|}{ Cyclin D1 } & \multicolumn{2}{|c|}{ EGFR } \\
\hline & & Positive (\%) & $\mathrm{P}$-value & Positive (\%) & P-value & Positive (\%) & P-value \\
\hline \multicolumn{8}{|l|}{ Tumor size } \\
\hline $\mathrm{T} 1 / 2$ & 110 & $48(44)$ & 0.3466 & $45(41)$ & 0.2766 & 43 (39) & 0.8089 \\
\hline $\mathrm{T} 3 / 4$ & 30 & $16(53)$ & & $9(30)$ & & $11(37)$ & \\
\hline \multicolumn{8}{|l|}{ Nodal metastasis } \\
\hline Negative & 103 & $44(43)$ & 0.2351 & 39 (38) & 0.7742 & $36(35)$ & 0.1421 \\
\hline Positive & 37 & $20(54)$ & & $15(41)$ & & $18(49)$ & \\
\hline \multicolumn{8}{|l|}{ Clinical stage } \\
\hline Stage I/II & 89 & $38(43)$ & 0.3437 & $34(38)$ & 0.9056 & $32(36)$ & 0.4008 \\
\hline Stage III/IV & 51 & $26(51)$ & & $20(39)$ & & $22(43)$ & \\
\hline \multicolumn{8}{|l|}{ Differentiation } \\
\hline Well & 73 & $30(41)$ & 0.4264 & $28(38)$ & 0.5208 & $19(26)$ & 0.0008 \\
\hline Moderate & 49 & $26(53)$ & & 17 (35) & & $22(45)$ & \\
\hline Poor & 18 & $8(44)$ & & $9(50)$ & & $13(72)$ & \\
\hline \multicolumn{8}{|l|}{ Growth pattern } \\
\hline Expansive & 31 & $13(42)$ & 0.6047 & $10(32)$ & 0.7018 & $8(26)$ & 0.0003 \\
\hline Moderately invasive & 73 & $32(44)$ & & $29(40)$ & & $22(30)$ & \\
\hline Markedly invasive & 36 & $19(53)$ & & $15(17)$ & & $24(67)$ & \\
\hline
\end{tabular}

pattern $(P=0.0003)$ (Table 2). Similar analysis was performed for the coexpression of these markers (Table 3). Of the 140 cases, $35(25 \%)$ were negative for any of these markers, $53(38 \%)$ displayed singlemarker expression, 37 (26\%) two-marker coexpression and $15(11 \%)$ coexpression of all three markers. The increased expression of molecular markers was significantly associated with progressing invasive growth pattern $(P=0.0149)$. In addition, the tumors with single or only one marker expression had a tendency towards well tumor differentiation, although there was no statistical significance $(P=0.0669)$.

\section{Association between Expression of Molecular Markers and Survival in Oral Cancers}

Figure 3 illustrates Kaplan-Meier overall survival curves for patients with oral cancer according to the expression of molecular markers. The expression of p53 was not associated with survival (Figure 3a). However, patients in the group with tumors expressing cyclin D1 (Figure 3b) or EGFR (Figure 3c) tended to have worse survival than the group negative for these markers, although the difference did not reach statistical significance $(P=0.0877$ and 0.0740 , respectively). Similar analysis was also performed for the simultaneous coexpression of these markers. Overall survival of patients deteriorated gradually with the increase in the coexpression of these markers, and the patient group with tumors positive for all three markers had significantly worse survival than the other groups $(P=0.0181)$.

Patients in the groups with tumors having expression of one or two markers did not show a significant difference in survival compared to the group without marker expression (Figure 3d). In a multivariate Cox hazards regression analysis, the 
Table 3 Relationships between expression of molecular markers and clinicopathological features in oral cancers

\begin{tabular}{|c|c|c|c|c|c|c|}
\hline \multirow[t]{2}{*}{ Variable } & \multirow[t]{2}{*}{$\mathrm{n}$} & \multicolumn{4}{|c|}{$\begin{array}{l}\text { Coexpression of } \\
\text { molecular markers }\end{array}$} & \multirow[t]{2}{*}{ P-value } \\
\hline & & 0 & 1 & 2 & 3 & \\
\hline \multicolumn{7}{|l|}{ Tumor size } \\
\hline $\mathrm{T} 1 / 2$ & 110 & 30 & 38 & 28 & 14 & 0.1973 \\
\hline $\mathrm{T} 3 / 4$ & 30 & 5 & 15 & 9 & 1 & \\
\hline \multicolumn{7}{|l|}{ Nodal metastasis } \\
\hline Negative & 103 & 29 & 39 & 25 & 10 & 0.4565 \\
\hline Positive & 37 & 6 & 14 & 12 & 5 & \\
\hline \multicolumn{7}{|l|}{ Clinical stage } \\
\hline Stage I/II & 89 & 26 & 31 & 23 & 9 & 0.4862 \\
\hline Stage III/IV & 51 & 9 & 22 & 14 & 6 & \\
\hline \multicolumn{7}{|l|}{ Differentiation } \\
\hline Well & 73 & 22 & 32 & 12 & 7 & 0.0669 \\
\hline Moderate & 49 & 12 & 14 & 18 & 5 & \\
\hline Poor & 18 & 1 & 7 & 7 & 3 & \\
\hline \multicolumn{7}{|l|}{ Growth pattern } \\
\hline Expansive & 31 & 12 & 10 & 6 & 3 & 0.0149 \\
\hline Moderately invasive & 73 & 18 & 34 & 14 & 7 & \\
\hline Markedly invasive & 36 & 5 & 9 & 17 & 5 & \\
\hline
\end{tabular}
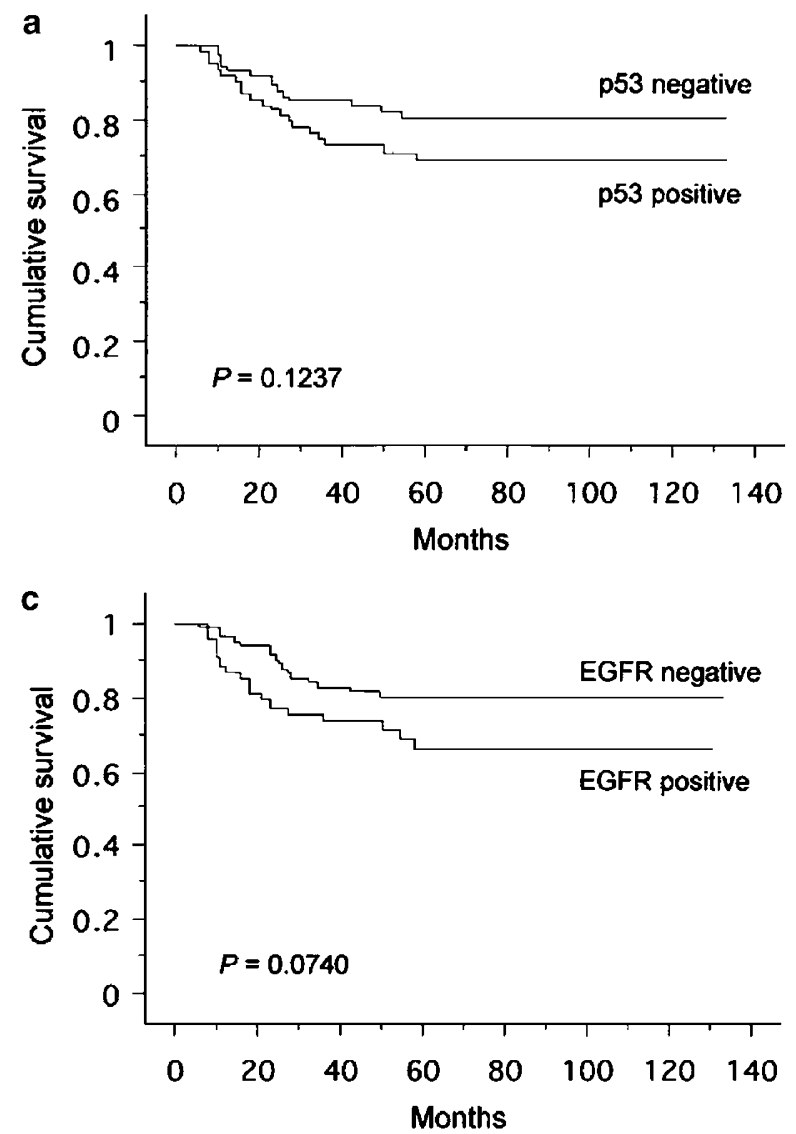

coexpression of all three molecular markers was identified as an independent prognostic factor of overall survival $(P=0.0019)$, along with tumor size $(P=0.0079)$, lymph node metastasis $(P=0.00190)$ and invasive growth pattern $(P=0.0003)$. The expression of any one or two of markers was not an independent prognostic factor (Table 4).

\section{Discussion}

In this study, immunohistochemistry was used to evaluate marker expression in tumors. This method lacks objective quantitation, but it avoids difficulties due to contamination by nontumorous cells and has the advantages of determining the positivity and expression pattern of a marker in tissue. However, results obtained by immunohistochemistry from clinical tumor samples are not always in good agreement among investigators. The differences could be related to the number of cases examined, treatment modality and immunohistochemical methodology. The selection of criteria applied to define a tumor as positive or negative are especially important, since they greatly affect the results.
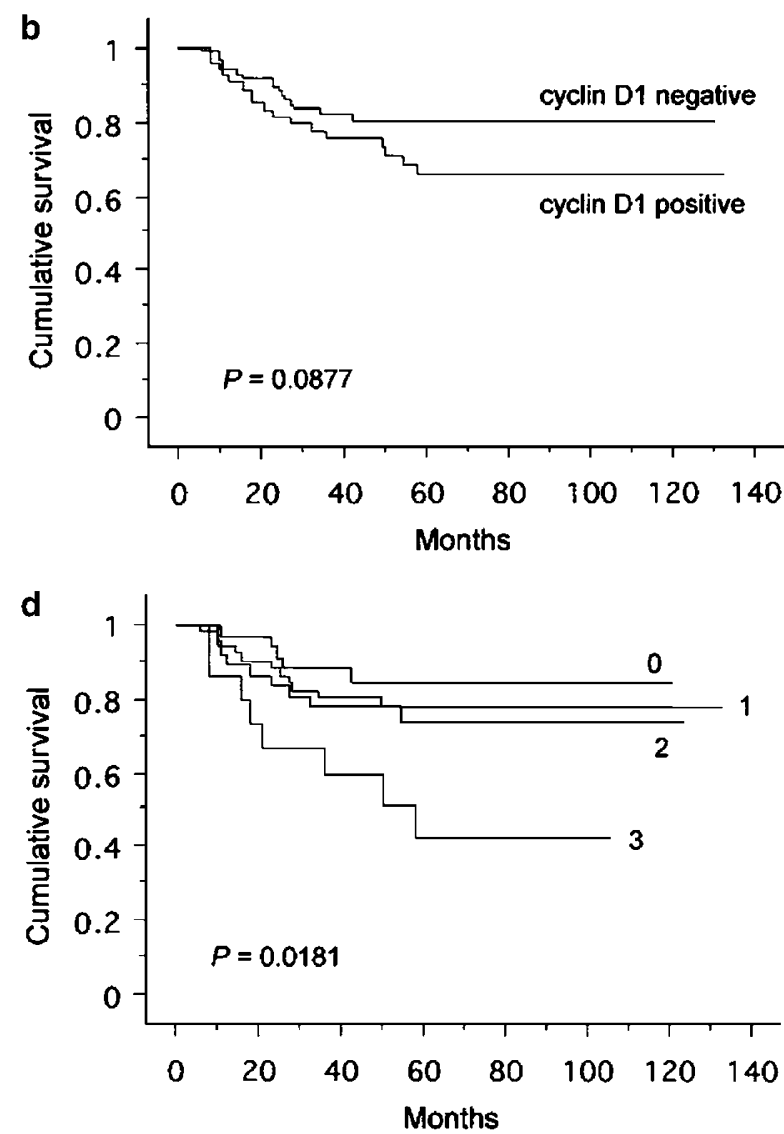

Figure 3 Kaplan-Meier overall survival curves of patients with oral SCC with respect to molecular marker expression. Patients are divided into two groups, negative and positive, depending on the expression for p53 (a), cyclin D1 (b) and EGFR (c), respectively. In addition, patients are divided into four groups, 0 for no expression, 1 for single expression of any marker, 2 for coexpression of any two markers and 3 for coexpression of all three markers, in the analysis for the simultaneous coexpression of these markers (d). 
Table 4 Cox's multivariate analysis of overall survival in patients with oral cancer

\begin{tabular}{|c|c|c|c|c|}
\hline Model & Variable & $H R^{\mathrm{a}}$ & $95 \% C I^{b}$ & $\mathrm{P}$-value \\
\hline A & $\begin{array}{l}\text { Tumor size } \\
\text { T1/2 } \\
\text { T3/4 }\end{array}$ & $\begin{array}{l}1 \\
2.784\end{array}$ & $1.308-5.926$ & 0.0079 \\
\hline & $\begin{array}{l}\text { Nodal metastasis } \\
\text { Negative } \\
\text { Positive }\end{array}$ & $\begin{array}{l}1 \\
2.516\end{array}$ & $1.163-5.439$ & 0.019 \\
\hline & $\begin{array}{l}\text { Differentiation } \\
\text { Well/moderate } \\
\text { Poor }\end{array}$ & $\begin{array}{l}1 \\
1.063\end{array}$ & $0.405-2.791$ & 0.9012 \\
\hline & $\begin{array}{l}\text { Growth pattern } \\
\text { Expansive/moderately } \\
\text { invasive } \\
\text { Markedly invasive }\end{array}$ & $\begin{array}{l}1 \\
3.963\end{array}$ & $1.881-8.349$ & 0.0003 \\
\hline B & $\begin{array}{l}\text { Stage } \\
\quad \text { Stage I/II } \\
\text { Stage III/IV }\end{array}$ & $\begin{array}{l}1 \\
3.743\end{array}$ & $1.838-7.622$ & 0.0003 \\
\hline & $\begin{array}{l}p 53 \\
\text { Negative } \\
\text { Positive }\end{array}$ & $\begin{array}{l}1 \\
1.54\end{array}$ & $0.771-3.076$ & 0.2212 \\
\hline & $\begin{array}{l}\text { Cyclin D1 } \\
\text { Negative } \\
\text { Positive }\end{array}$ & $\begin{array}{l}1 \\
1.679\end{array}$ & $0.843-3.345$ & 0.1407 \\
\hline & $\begin{array}{l}\text { EGFR } \\
\text { Negative } \\
\text { Positive }\end{array}$ & $\begin{array}{l}1 \\
1.653\end{array}$ & $0.831-3.291$ & 0.1523 \\
\hline $\mathrm{C}$ & $\begin{array}{l}\text { Stage } \\
\quad \text { Stage I/II } \\
\text { Stage III/IV }\end{array}$ & $\begin{array}{l}1 \\
4.008\end{array}$ & $1.964-8.178$ & 0.0001 \\
\hline & $\begin{array}{l}\text { Coexpression of molecular } \\
\text { markers } \\
\text { 0/1/2 marker expression } \\
3 \text { marker expression }\end{array}$ & $\begin{array}{l}1 \\
3.561\end{array}$ & $1.598-7.936$ & 0.0019 \\
\hline
\end{tabular}

${ }^{\mathrm{a}}$ Hazard ratios from Cox models.

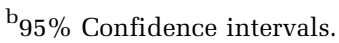

Therefore, it would be desirable to compare results of studies conducted using similar immunohistochemical criteria.

Mutation of the p53 gene has been implicated in the development of $>50 \%$ of all human cancers. The majority of the p53 mutations appear as missense mutations that closely correlate with accumulation of mutant p53 protein. ${ }^{27}$ However, mutation of p53 is not always correlated with its protein expression in human cancers. The reason for this observation is unclear. Some of the tumors positive for p53 may be accumulating wild-type functional p53, since levels of p53 can be stabilized by interactions with other intracellular proteins such as mdm-2, leading to immunohistochemical expression. ${ }^{28-30}$ In addition, p53 mutations resulting in a stop codon, frameshift, or nonsense mutations may result in altered or truncated proteins that are not detected by immunohistochemistry. ${ }^{2}$ In human cancers, accumulation of p53 has been shown to be a good indicator of poor prognosis. ${ }^{10,13,20}$ In this study, we found p53 expression in $46 \%$ of the 140 tumors investigated, which is lower than the reported $64 \%{ }^{31}$ but similar to that ${ }^{23,32}$ found in head and neck cancers, when examined using the same antibody and cutoff value. Our data, however, confirmed the results of previous studies that failed to establish an association of p53 expression with survival in head and neck cancers. ${ }^{31,32}$ The absence of an impact of p53 expression on tumor progression might possibly be explained by recent studies that report the predictive value of p53 mutation $^{33}$ and mutation within DNA-binding surface region of p5 $3^{34}$ for shortened survival rather than p53 protein expression in head and neck cancers. More comprehensive studies combined with mutational analysis are required for determining the outcomes of cancer patients using immunohistochemistry.

In this study, cyclin D1 was expressed in 54 cases $(39 \%)$, which is higher than the $19 \%$ reported for head and neck cancers ${ }^{22}$ and $33 \%$ for esophageal cancer ${ }^{12}$ but similar to that in another report on esophageal cancer, ${ }^{18}$ when examined using the same antibody and cutoff value as in this study. Amplification of the cyclin D1 gene and the subsequent protein expression have been reported to be associated with disease progression ${ }^{9,22}$ and reduced survival $^{9,14,16}$ in head and neck cancers. In our series, however, cyclin D1 expression was associated with neither disease progression nor survival. The lack of impact of cyclin D1 expression on tumor progression in our study may be, in part, explained by other roles of cyclin D1 such as induction of apoptosis ${ }^{35}$ and involvement in p21- and wild-type p53-mediated growth arrest ${ }^{36}$ or Rb-related tumor growth suppression. ${ }^{37}$ Surprisingly, cell cycle progression is changeable in response to the amount and timing of cyclin D1 influencing the cell cycle, ${ }^{38}$ and the decision for cell growth or arrest may depend on the concentration of cyclin D1. ${ }^{10}$ Thus, cyclin D1 seems to function not only as a regulator in G1/S transition under ordinary circumstances but also as a negative regulator of cell proliferation in different situations. ${ }^{39}$ Therefore, cautious consideration should be given to the results of the cyclin D1 expression for prognostic evaluation because of the complex roles of cyclin D1.

The activation of the growth factor receptor is important in tumor development and invasive tumor growth. EGFR influences important steps of tumor invasion and dissemination. ${ }^{40}$ The significance of EGFR as a high-risk indicator for disease progression or poor prognosis has been described for head and neck cancers. ${ }^{8,11,21}$ In general, EGFR immunoreactivity is located in the cell membrane, but there is currently a debate on the interpretation of cytoplasmic staining of EGFR. ${ }^{41}$ We included the cytoplasmic staining of EGFR in the results to be evaluated because this 
abnormal staining was assessed to be important and specific like membranous staining in another study of oral cancer. ${ }^{21}$ In this study, we found EGFR expression in 54 cases (39\%), which is within the range from $37^{21}$ to $51 \%{ }^{42}$ reported for oral cancer examined using the same scoring system for criteria as in our study. In addition, in our cases, EGFR expression was significantly related to an invasive growth pattern, but this expression, unexpectedly, was associated with neither the disease progression nor survival for cancer patients, which is consistent with a previous report. ${ }^{24}$ Our data, however, do not completely deny the usefulness of EGFR as a marker for prognosis because EGFR expression tends to be correlated with survival $(P=0.0740)$. The reason for the lack of impact of EGFR expression on prognosis is unclear, but this may be due to the backgrounds of the cases examined or immunohistochemical tissue heterogeneity.

Next, we examined the impact of coexpression of molecular markers on tumor progression. The coexpression of these markers was found to be significantly associated with an invasive growth pattern and worse survival. Patient survival was significantly reduced with the increase in the coexpression of markers. Patients with tumors simultaneously expressing all three markers had a significantly worse prognosis than groups with no, single- or twomarker expression. In addition, the coexpression of all three markers was selected as an independent prognostic factor in multivariate analysis, together with tumor size, lymph node metastasis and invasive growth pattern, which is consistent with recent studies. ${ }^{21,43}$ Such coexpression of multiple molecular markers is in close agreement with the fundamental concept of multistep cancer development and progression. Immunohistochemical analysis using multiple molecular markers for prognostic evaluation can provide us with even more useful information than the use of one or two markers.

In conclusion, our study should be extremely valuable for the determination of treatment strategies in future studies. Multiple marker testing may have a great value in identifying high-risk oral SCC patients before surgery and in selecting patients who will benefit from intensive adjuvant therapy.

\section{Acknowledgements}

This work was supported by a Grant-in-Aid for Scientific Research from the Ministry of Education and Science of Japan.

\section{References}

1 Scully C, Field JK, Tanzawa H. Genetic aberrations in oral or head and neck squamous cell carcinoma 3: clinico-pathological applications. Oral Oncol 2000;36: 404-413.
2 Harris CC, Hollstein M. Clinical implications of the p53 tumor-suppressor gene. N Engl J Med 1993;329: 1318-1327.

3 Levine AJ, Momand J, Finlay CA. The p53 tumor suppressor gene. Nature 1991;351:453-456.

4 Finlay CA, Hinds PW, Tan TH, et al. Activating mutations for transformation by p53 produce a gene product that forms a hsc70-p53 complex with an altered half-life. Mol Cell Biol 1988;8:531-539.

5 Sherr CJ. Cancer cell cycles. Science 1996;274: 1672-1677.

6 Weinberg RA. The retinoblastoma protein and cell cycle control. Cell 1995;81:323-330.

7 Plowman GD, Whitney GS, Neubauer MG, et al. Molecular cloning and expression of an additional epidermal growth factor receptor-related gene. Proc Natl Acad Sci USA 1990;87:4905-4909.

8 Ang KK, Berkey BA, Tu X, et al. Impact of epidermal growth factor receptor expression on survival and pattern of relapse in patients with advanced head and neck carcinoma. Cancer Res 2002;62:7350-7356.

9 Bova RJ, Quinn DI, Nankervis JS, et al. Cyclin D1 and p16 ${ }^{\text {INK4A }}$ expression predict reduced survival in carcinoma of the anterior tongue. Clin Cancer Res 1999; 5:2810-2819.

10 Gansauge S, Gansauge F, Ramadani M, et al. Overexpression of cyclin D1 in human pancreatic carcinoma is associated with poor prognosis. Cancer Res 1997;57:1634-1637.

11 Grandis JR, Melhem MF, Gooding WE, et al. Levels of TGF- $\alpha$ and EGFR protein in head and neck squamous cell carcinoma and patient survival. J Natl Cancer Inst 1998;90:824-832.

12 Itami A, Shimada Y, Watanabe G, et al. Prognostic value of $\mathrm{p} 27^{\mathrm{Kip} 1}$ and cyclin D1 expression in esophageal cancer. Oncology 1999;57:311-317.

13 Kaur J, Srivastava A, Ralhan R. Prognostic significance of p53 protein overexpression in betel- and tobaccorelated oral oncogenesis. Int J Cancer 1998;79:370-375.

14 Kyomoto R, Kumazawa H, Toda M, et al. Cyclin D1 gene amplification is a more potent prognostic factor than its protein over-expression in human head-andneck squamous-cell carcinoma. Int J cancer 1997;74: $576-581$.

15 Mineta H, Miura K, Takebayashi S, et al. Cyclin D1 overexpression correlates with poor prognosis in patients with tongue squamous cell carcinoma. Oral Oncol 2000;36:194-198.

16 Miyamoto R, Uzawa N, Magaoka S, et al. Prognostic significance of cyclin d1 amplification and overexpression in oral squamous cell carcinomas. Oral Oncol 2003;39:610-618.

17 Mukaida H, Toi M, Hirai T, et al. Clinical significance of the expression of epidermal growth factor and its receptor in esophageal cancer. Cancer 1991;68:142-148.

18 Shimada Y, Imamura M, Uchida S, et al. Prognostic factors of oesophageal squamous cell carcinoma from the perspective of molecular biology. $\mathrm{Br} \mathrm{J}$ Cancer 1999;80:1281-1288.

19 Shimaya K, Shiozaki H, Inoue M, et al. Significance of p53 expression as a prognostic factor in oesophageal squamous cell carcinoma. Virchows Archiv A Pathol Anat 1993;422:271-276.

20 Shin DM, Lee JS, Lippmann SM, et al. p53 expression: predicting recurrence and second primary tumors in head and neck squamous cell carcinoma. J Natl Cancer Inst 1996;88:519-529. 
21 Xia W, Lau YK, Zhang HZ, et al. Combination of EGFR, HER-2/neu, and HER-3 is a stronger predictor for the outcome of oral squamous cell carcinoma than any individual family members. Clin Cancer Res 1999;5: 4164-4174.

22 Fracchiolla NS, Pruneri G, Pignataro L, et al. Molecular and immunohistochemical analysis of the bcl-1/cyclin D1 gene in laryngeal squamous cell carcinomas. Correlation of protein expression with lymph node metastases and advanced clinical stage. Cancer 1997; 79:1114-1121.

23 Sittel C, RuiZ S, Volling P, et al. Prognostic significance of Ki-67 (MIB1), PCNA and p53 in cancer of the oropharynx and oral cavity. Oral Oncol 1999;35:583-589.

24 Ulanovsky D, Stern Y, Roizman P, et al. Expression of EGFR and Cerb-B2 as prognostic factors in cancer of the tongue. Oral Oncol 2004;40:532-537.

25 Tanaka N, Odajima T, Ogi K, et al. Expression of Ecadherin, $\alpha$-catenin, and $\beta$-catenin in the process of lymph node metastasis in oral squamous cell carcinoma. Br J Cancer 2003;89:557-563.

26 Kersemaekers AMF, Fleuren GJ, Kenter GG. Oncogene alterations in carcinomas of the uterine cervix: overexpression of the epidermal growth factor receptor is associated with poor prognosis. Clin Cancer Res 1999;5:577-586.

27 Greenblatt MS, Bennett WP, Hollstein M, et al. Mutations in p53 tumor suppressor gene: clues to cancer etiology and molecular pathogenesis. Cancer Res 1994;54:4855-4878.

28 Hainaut P, Milner J. Interaction of heat-shock protein 70 with p53 translated in vitro: evidence for interaction with dimeric p53 and for a role in the regulation of p53 conformation. EMBO J 1992;11:3513-3520.

29 Momand J, Zambetti GP, Olson DC, et al. The mdm-2 oncogene product forms a complex with the p53 protein and inhibits p53-mediated transactivation. Cell 1992;69:1237-1245.

30 Yew PR, Berk AJ. Inhibition of p53 transactivation required for transformation by adenovirus early $1 \mathrm{~B}$ protein. Nature 1992;357:82-85.

31 Nylander K, Stenling R, Gustafsson H, et al. p53 expression and cell proliferation in squamous cell carcinomas of the head and neck. Cancer 1995;75:87-93.
32 Obata A, Eura M, Sssaki J, et al. Clinical significance of p53 functional loss in squamous cell carcinoma of the oropharynx. Int J,Cancer 2000;89:187-193.

33 Mineta H, Borg A, Dictor M, et al. p53 mutation, but not p53 overexpression, correlates with survival in head and neck squamous cell carcinoma. Br J Cancer 1998;78:1084-1090.

34 Yamazaki Y, Chiba I, Hirai A. Specific p53 mutations predict poor prognosis in oral squamous cell carcinoma. Oral Oncol 2003;39:163-169.

35 Kotelnikov VM, Coon IV JS, Mundle S. Cyclin D1 expression in squamous cell carcinomas of head and neck in oral mucosa in relation to proliferation and apoptosis. Clin Cancer Res 1997;3:95-101.

36 Del Sal G, Murphy M, Ruaro E, et al. Cyclin D1 and p21/waf1 are both involved in p53 growth suppression. Oncogene 1996;12:177-185.

37 Müller H, Lukas J, Schneider A. Cyclin D1 expression is regulated by the retinoblastoma proteins. Proc Natl Acad Sci USA 1994;91:2945-2949.

38 Pagano M, Theodoras AM, Tam SW, et al. Cyclin D1-mediated inhibition of repair and replicative DNAsynthesis in human fibroblasts. Genes Dev 1994;8: 1627-1639.

39 Anton RC, Coffey DM, Gondo MM, et al. The expression of cyclin D1 and $\mathrm{E}$ in predicting short-term survival in oral squamous cell carcinoma of the lung. Mod Pathol 2000;13:1167-1172.

40 Khazaie K, Schirrmacher V, Lichtner RB. EGF receptor in neoplasia and metastasis. Cancer Metast Rev 1993; 12:255-274.

41 De Potter CR, Quatacker J, Aertens G, et al. The subcellular localization of the neu protein in human normal and neoplastic cells. Int J Cancer 1999;44: 969-974.

42 Bei R, Pompa G, Vitolo D, et al. Co-localization of multiple ErbB receptors in stratified epithelium of squamous cell carcinoma. J Pathol 2001;195: 343-348.

43 Schneider PM, Praeuer HW, Stoeltzing O, et al. Multiple molecular marker testing (p53, C-Ki-ras, cerbB-2) improves estimation of prognosis in potentially curative resected non-small cell lung cancer. Br J Cancer 2000;83:473-479. 